\title{
LA LIBERTAD AGUSTINIANA
}

\author{
María del Carmen Dolby Múgica \\ IES Cantabria (Santander)
}

\section{RESUMEN}

La concepción agustiniana de la libertad se va fraguando al hilo de sus polémicas con los maniqueos y pelagianos. Agustín defiende la existencia de la libertad frente a los maniqueos y la considera la causante del mal o pecado así como capaz de méritos. Frente a los pelagianos afirma que el liberum arbitrium necesita de la gracia de Dios para hacer el bien y de este modo llegar a un grado más perfecto de libertad, la libertas, que consiste en le necesidad de hacer el bien. La meta de la libertad no es otra que Dios, sumo Bien y felicidad para el hombre.

Palabras clave: San Agustín, Dios, liberum arbitrium, libertas, mal, pecado, maniqueos, pelagianos, Bien, felicidad, gracia.

\begin{abstract}
Saint Augustine conception of freedom forges through his polemics with Manichees and Pelagians. Augustine defends the existence of freedom against the Manichees and he considerates it the real cause of evil or sin as well as capable of obteining merits. Face to Pelagians he affirms that liberum arbitrium needs God grace to do good arriving to a more perfect freedom, libertas, which consists in the need to do the good. The goal of freedom is God, man's highest good and happiness.
\end{abstract}

Key words: Saint Augustine, God, liberum arbitrium, libertas, evil, sin, Manichees, Pelagians, Good, happiness, grace.

\section{INTRODUCCIÓN}

La libertad es una de las temáticas más emblemáticas del debate filosófico y una de las cuestiones que ha generado mayores controversias en el quehacer dialéctico y argumentativo. La razón de todo ello no ès otra que la de ser una de las capacidades más distintivas del ser humano y la que le permite, en última instancia, hacerse como persona.

San Agustín, al que podemos caracterizar como un filósofo apasionado por el hombre y su libertad, la analiza desde una perspectiva teísta en polémica con los maniqueos y con los pelagianos, durante los siglos IV y V d. C.

Su punto de partida no es otro que el de una libertad humana ya no sólo limitada sino deteriorada por el pecado, verdadera causa del mal. Así concebida la libertad humana necesitará, para poder forjar al auténtico ser humano, al hombre nuevo, de la cooperación y ayuda de Dios. La libertas, o libertad verdadera, es un objetivo que no sólo depende de la acción humana sino que depende, en gran medida, del apoyo que reciba de Dios.

La filosofía agustiniana, cuyo gozne no es otro que las temáticas de Dios y del hombre, es congruente, también en el tema de la libertad, coil este presupuesto, desarrollando y desvelando el ser verdadero de la libertad, tanto desde la perspectiva de la voluntad humana como de la divina. 
A diferencia de las filosofias ateas que ven en Dios al gran negador de la libertad humana y al hombre como portador de una libertad sin límites, absolutamente creadora, san Agustín es consciente de la limitación de nuestra libertad, cuya única posibilidad de subsistencia radica en la elección de un Bien superior a ella, que lejos de fundar, la plenifica tanto en el orden ontológico como en el orden moral.

La limitación ontológica del hombre estaría reñida con una libertad absoluta, sin límites. Sólo a un Ser Absoluto puede corresponderle una libertad total, fundadora de valores, a menos que el hombre pasase a ocupar el puesto de Dios y se erigiese en juez supremo del Bien y del Mal. Este es el salto que la filosofia atea de los siglos XIX y XX ha llevado a cabo.

Ante esta disyuntiva, Dios o el hombre, es esclarecedor acercarse al planteamiento agustiniano que, lejos de minimizar al hombre dependiente de Dios, lo engrandece y le otorga su verdadero puesto en la obra de la Creación.

\section{LA CONCEPCIÓN DE LA LIBERTAD EN SAN AGUSTÍN}

\section{El debate con los maniqueos}

Nos podríamos preguntar cuál fue la causa que le llevó a san Agustín a plantearse la temática de la libertad. La respuesta la hallamos en su preocupación por encontrar una solución al problema del mal. Desde esta perspectiva comenzaría la andadura agustiniana de la libertad.

Desde joven, Agustín mostró ser ya una mente inquisidora que buscaba una explicación para todas aquellas cuestiones que le inquietaban profundamente: el origen del mundo, Dios, la esencia del hombre y su destino. No obstante al hilo de todas ellas, se encontraba su preocupación por averiguar la verdadera naturaleza del mal y dar de ella una explicación racional.

Desde muy joven, como lo hizo el propio Sidharta, descubrió la existencia del mal en el mundo, tanto desde un punto de vista objetivo como desde una vivencia personal del mismo. En su estancia en la ciudad de Cartago, halló una ciudad atravesada por el mal, pudiendo comprobar por todas partes la corrupción de las costumbres, las luchas entre las personas y la relajación de los lazos sociales: «Llegué a Cartago, y por todas partes crepitaba en torno mío un hervidero de amores impuros» ${ }^{1}$. No obstante la experiencia más importante que tuvo del mal vino de la mano de su amigo, muerto prematuramente. Su desàparición le causó un gran dolor y le hizo toparse con fuerza con la realidad del sufrimiento, consecuencia inmediata del mal. En su obra autobiográfica, Confesiones, nos la narra cargada de dramatismo: «Llevaba el alma rota y ensangrentada, impaciente de ser llevada por mí, y no hallaba dónde ponerla. Ni descansaba en los bosques amenos, ni en los juegos y cantos, ni en los lugares olorosos, ni en los banquetes espléndidos, ni en los deleites del lecho y del hogar, ni, finalmente, en los libros ni en los versos. Todo me causaba horror, hasta la misma luz; y cuanto no era lo que él era me resultaba insoportable y odioso, fuera de gemir y llorar, pues sólo en esto hallaba algún descanso. Y si apartaba de esto a mi alma, luego me abrumaba la pesada carga de mi miseria» ${ }^{2}$. Ante un hecho de tal envergadura y que tan honda huella le dejó, la única opción que le quedaba a Agustín era la de lanzarse a la búsqueda de una explicación para el mal en el mundo. $\mathrm{Y}$ justamente, entre muchas otras, vino a toparse con una secta, el Maniqueísmo, que le prometía y ofrecía la solución a su problema. Agustín no dudó ni un momento en comprometerse con ella y en aceptar sus propuestas que llevaban aparejada, como veremos, la negación de la libertad humana y por consiguiente su responsabilidad en el ámbito moral.

1 Conf. I, I, 1

2 Conf. IV, VII, 12 
¿Cuáles fueron las principales tesis maniqueas que atenazaron el pensamiento agustiniano en una maraña de nudos, dificiles de desenredar y que le hicieron permanecer en dicha secta, tal y como nos lo cuenta en las Confesiones, nueve años de su vida: «Durante este espacio de tiempo de nueve años - desde los diecinueve de mi edad hasta los veintiocho- fuimos seducidos y seductores, engañados y engañadores (Tim. 2, 3-13), según la diversidad de nuestros apetitos; públicamente por medio de aquellas doctrinas que llaman liberales; ocultamente, con el falso nombre de religión, siendo aquí soberbios y allí supersticiosos, en todas partes vanos $»^{3}$.

Las principales teorias de los maniqueos se centraban en la creación del mundo, en la concepción de Dios, en su explicación del mal y en su idea del hombre.

Con respecto a la creación del mundo, reconocían la presencia no sólo de Dios sino del mal, del que hacían una realidad tal y como nos lo narra san Agustín: «Erraron los maniqueos. Dicen que antes de la creación del mundo había una gente de las tinieblas que se rebeló contra Dios. Creen los infelices que en aquella lucha no pudo el Omnipotente defenderse de otro modo que lanzando contra aquella gente, una parte de su divina sustancia. Los príncipes de aquella gente, según ellos, devoraron la parte de sustancia divina y quedaron de tal modo sosegados, que pudo con ellos fabricarse el mundor ${ }^{4}$.

La primera consecuencia inmediata de este planteamiento fue hacer de Dios no sólo un Ser limitado sino corpóreo: «iOh verdad, verdad, cuán íntimamente suspiraba entonces por ti desde los meollos de mi alma, cuando aquellos te hacían resonar en torno mío frecuentemente y de muchos modos, bien que sólo de palabras y en sus muchos y voluminosos libros. Éstos eran las bandejas en las que, estando yo hambriento de ti, me servían en tu lugar el sol y la luna, obras tuyas hermosas, pero al fin obras tuyas, no tú y ni aún siquiera de las principales. Porque más excelentes son tus obras espirituales que estas corporales, siquiera lúcidas y celestes...Mas tú, amor mío, en quien desfallezco para ser fuerte, ni eres estos cuerpos que vemos, aunque sea en el cielo, ni los otros que no vemos allí, porque tú eres el Criador de todos éstos, sin que los tengas por las más altas creaciones de tus manos. ¡Oh cuán lejos estabas de aquellos mis fantasmas imaginarios, fantasmas de cuerpos que no han existido jamás, en cuya comparación son más reales las imágenes de los cuerpos existentes; y más aún que aquéllas, éstos, los cuales, sin embargo no eres tú! Pero ni siquiera eres el alma que da vida a los cuerpos y como la vida de los cuerpos, mejor y más cierta que los cuerpos- sino que tú eres la vida de las almas, la vida de las vidas que vives por ti misma y no te cambias: la vida de mi alma» ${ }^{5}$.

La segunda consecuencia también inmediata del mismo planteamiento recaería sobre la concepción del hombre y de su libertad, o mejor dicho de su falta de libertad: «Vosotros (los maniqueos) decís que el alma es Dios o una parte de Dios. En verdad que no comprendo que una parte de Dios no sea realmente Dios» ${ }^{6}$. «Sostienen que en un mismo cuerpo habitan dos almas; una divina, que naturalmente es como Dios; otra oriunda de la raza de las tinieblas a la que Dios ni engendró, ni hizo ni produjo, ni rechazó pero que tiene su vida, su tierra, sus animales, su reino, en fin y su principio improductos? ${ }^{7}$.

Las conclusiones que podemos sacar de estos textos son la siguientes: la primera sería que el mal tiene una entidad propia y que afecta por igual a Dios y al hombre. La segunda incidiría en el centro mismo de la conducta humana por cuanto ésta ya no sería la causa determinante de una mala acción sino su parte de tinieblas que la forzaría a cometerla. Se niega así la libertad del hombre en la ejecución de una acción mala y su consiguiente responsabilidad moral.

3 Conf. IV, I, 1; Cfr., Maniqueísmo en Brown, P., Agustin, Madrid, Acento, 2001, p.49

De agone christ. IV,4

Conf. III VI, 11

De mor. eccl. cath. et de mor. Man. II, XI, 21

De vera relig. IX, XVI 
Un planteamiento de este tipo, necesariamente llevaría a una moral externa, cargada de prácticas de purificación y de rituales que poco tienen que ver con la auténtica moral que comienza siempre en el interior del ser humano, en su primera intencionalidad para ser luego continuada en su libre elección y actuación ${ }^{8}$.

Agustín como verdadero intelectual que busca siempre la verdad, se daría cuenta, aunque después de un largo y dificultoso camino, de los errores maniqueos, tanto científicos, religiosos como metafísicos. Al calor del neoplatonismo del Círculo de Milán, liderado por el obispo Ambrosio se;acercaría no sólo a la comprensión auténtica de la naturaleza del mal sino al descubrimiento de las realidades espirituales y de la importancia del libre arbitrio en la ejecución del mal. El investigador de san Agustín, Victorino Capánaga nos indica los pasos que hubo de dar Agustín para empezar a resolver todos su enigmas, entre los cuales iba incluido el de la libertad humana: «San Agustín dio a lo menos los siguientes pasos: $1^{\circ}$., descubrió las contradicciones internas del maniqueísmo y la falsedad de su metafísica del mal. El mal no es sustancia, sino privación. Todas las cosas naturales son buenas, «Omne quod naturaliter est, bonum est» (De natura boni, XIX, 19); $2^{\circ}$., adquirió el sentimiento de la propia responsabilidad o fuerza del libre albedrío, como causa del mal; $3^{\mathbf{a}}$., halló la espiritualidad del alma hasta entonces considerada como sustancia material o mezcla de dos sustancias, una luminosa y otra tenebrosa; $4^{\circ}$., más tarde con los dogmas cristianos de la Creación, Encarnación, Resurrección de Cristo y Resurrección universal, quedó definitivamente clarificada la nueva ontología antignóstica y antimaniquea» ${ }^{9}$.

Agustín, pertrechado con la nueva ontología, comienza entonces su refutación del Maniqueísmo y su defensa de la libertad humana, plasmada especialmente en su obra De libero arbitrio.

En ella destaca la contundencia con la que se afirma la existencia del libre albedrío tanto para la ejecución del mal como del mismo bien. En sus diálogos con Evodio, se van aclarando dificultades y sobre todo se van asentando las bases de lo que será la verdadera concepción agustiniana de la libertad, que dependiendo de Dios en todo momento, conserva siempre su autonomía. En este diálogo al igual que en muchas otras obras, Agustín va a hacer hincapié en el aspecto positivo de la libertad, es decir, en una libertad que es necesaria para la elección y obtención de los bienes y en última instancia del Bien que nos procurará la auténtica felicidad a la que por naturaleza estamos abocados y frente a la cual no somos libres pues hagamos lo que hagamos, siempre y en todo momento estará presente nuestro deseo de ser felices.

En una de las primeras intervenciones de Evodio, se planteà de inmediato la cuestión clave: «Dime: ¿Cuál es el origen del mal?» ${ }^{10}$. A esta pregunta responde de inmediato san Agustín diciendo: « ¡Ah! Suscitas precisamente aquella cuestión que tanto me atormentó a mí siendo aún muy joven, y que, después de haberme fatigado inútilmente en resolverla, me empujó e hizo caer en la herejía de los maniqueos ${ }^{11}$.

En este primer período de su vida, su concepción de la libertad se gesta al hilo de la polémica antimaniquea. Frente a las tesis maniqueas san Agustín quiere dejar aclaradas las siguientes afirmaciones: Dios no es causante del mal pero tampoco lo padece, sólo el libre albedrío es la causa del mal o del pecado y a la vez es capaz de méritos por los bienes realizados. Por último y como consecuencia de lo anterior, rechaza la existencia de dos almas en el hombre y niega que sea el alma procedente del mal, la que actúe en nosotros. Con todos estos pre-

8 Cfr., Dolby Múgica, C., Agustín de Tagaste: «El itinerario de la Sabiduría», en Revista Agustiniana, 90 (1988), pp.435-500 y «El problema del mal en san Agustín y la racionalidad de lo real», en Revista Agustiniana, 93 (1989), pp. 437-454.

9 Capánaga, V., «Materia y espíritu en el problema del mal según san Agustín», en Augustinus, 6 (1961), pp.169-178, concretamente en el capítulo II, La nueva ontología, p. 172-173.

10 De lib. arb. I, II, 4

11 De lib. arb. I, II, 4 
supuestos, queda expedita la vía de la investigación de la libertad, dado que en esta primera época de su vida su fuerza argumentativa se decantaría en la defensa a ultranza de aquella frente a la postura maniquea. Veremos cómo en la evolución de su pensamiento y especialmente en el cambio de sus oponentes, la perspectiva de la libertad variará pero siempre sosteniendo su existencia en el ser humano.

Pasemos a ver y a analizar algunos textos que confirman nuestras afirmaciones: «Creemos que hay un solo y único Dios y que de El procede todo cuanto existe, y que, no obstante, no es Dios el autor del pecado» ${ }^{12}$. En su debate con Fortunato dice: «Nuestra fe, en cambio, es ésta: Dios ni ha engendrado mal alguno ni ha hecho naturaleza mala alguna. Y como los dos estamos de acuerdo en que Dios no está sujeto a corrupción o mancha alguna, es propio de personas sabias y creyentes valorar qué fe es más pura y:más digna de la majestad de Dios: la que afirma que una fuerza, o una parte, o una palabra desios puede sufrir cambio, violación, corrupción o sujeción, o la otra que afirma que Dios todopoderoso y toda su naturaleza y sustancia nunca puede estar sujeta a corrupción en ninguna de sus partes, y que los males proceden del pecado voluntariamente cometido por el alma, a la que Dios dotó de libre albedrío» ${ }^{13}$. Esta es la aserción clave. Sin embargo a partir de ella se va a plantear una pregunta importante: «Si el pecado procede de las almas que Dios creó, y las almas vienen de Dios, ¿cómo no referir a Dios el pecado, siendo tan estrecha la relación entre Dios y el alma pecadora?» ${ }^{14}$. Para responder a esta espinosa cuestión, lo primero que tiene que hacer Agustín es demostrar que el libre albedrío es un bien y que Dios nos lo ha dado para obrar rectamente aunque con la posibilidad de hacer de él un mal uso: «Ev.- Tratemos ahora de la tercera cuestión, a saber, si puede demostrarse que la voluntad libre del hombre debe ser considerada como un bien. Demostrado esto, te concederé sin género de duda, que Dios nos la ha dado y que convino que nos la diera. Ag.- Tú has dicho, que parecía que no debía habernos dado el libre albedrío de la voluntad, porque de él se sirve el hombre para pecar. Habiéndote yo replicado que no se podía obrar bien sino mediante el mismo albedrío de la voluntad, y habiéndote probado que Dios nos lo dio principalmente para esto, tú respondiste que debía habernos dado la voluntad libre, como se nos dio la justicia, con la cual nadie puede obrar sino justamente. Esta respuesta fue la que me obligó a dar en el curso de la discusión un sinnúmero de rodeos, con el fin de demostrarte que todos los bienes, así mayores como los menores, provienen de Dios... Aunque estas dos verdades, que hay Dios y que todos los bienes proceden de Dios, fueran ya antes para nosotros objeto de nuestra fe inquebrantable, sin embargo, de tal manera las hemos dilucidado ahora, que también aparece como evidente esta tercera, o sea, que la voluntad libre del hombre ha de ser considerada como uno de los bienes que el hombre ha recibido de Dios» ${ }^{15}$.

En efecto, la voluntad libre del hombre además de ser un bien recibido de Dios es la condición indispensable para el mérito y el premio de las buenas obras. Esto no impide que el

12 Ibid. «Es cierto que Agustín, en su polémica contra los maniqueos, ha puesto en primer lugar el libre arbitrio, al que ha consagrado uno de sus tratados: De libero arbitrio. Desde el siglo II los autores cristianos luchaban contra las herejías gnósticas, insistiendo sobre el libre albedrío del hombre... Hacer a la libertad humana capaz del mal comporta al mismo tiempo dos cosas. Es decir, para explicar la presencia del mal en el mundo se evita el recurso a un mal sustancial, ontológico, a un Dios del mal, y al mismo tiempo se trata de exonerar de toda responsabilidad al Dios único y perfecto», Vergéz, A., «San Agustín y la filosofia cristiana», en Augustinus, 19 (1974), pp.319 , en p. 4.

13 C. Fort, 20

14 De lib. arb. I, II, 4

15 De lib. arb. II, XVIII, 47; «Semejante a este hombre, son aquellos que, viendo en su mente, y con muchísima razón, que sería mejor una criatura que, aunque dotada de libertad, hubiera, sin embargo, permanecido siempre unida a Dios, sin haber pecado jamás, al ver los pecados de los hombres se duelen de ellos, no porque quieran dejar de pecar, sino porque quisieran no haber sido creados en condiciones de pecar... Mas yo les digo: No clamen, no censuren al creador, pues Dios no les ha obligado a pecar por el hecho de haberlos creado y haberles dado el poder de querer o no querer pecar»), De lib. arb. III, V, 14 
hombre hága un mal uso de ella, tanto en la elección de bienes inferiores por encima de aquellos que son superiores como cuando abusa de su poder y peca. Esta última posibilidad está siempre presente en la libertad humana aunque Agustín deje bien claro que no fue ésta la finalidad para la cual se le otorgó al hombre: «Por consiguiente, así como concedes que son bienes estos del cuerpo y alabas al dador de estos bienes, no obstante el mal uso que muchos hacen de ellos, del mismo modo debes conceder que la voluntad libre, sin la cual nadie puede vivir rectamente, es un bien dado por Dios y que son dignos de nuestra reprobación y debemos reprobar a los que abusan de ella, antes que decir que no debió habérnosla dado el que nos la dio» ${ }^{16}$.

Son múltiples los textos en los que Agustín deja bien claro que la causa del mal o del pecado no es otra que el libre albedrío de nuestra voluntad. Es interesante resaltar el siguiente texto pues no servirá de puente para iniciar la tercera réplica a los maniqueos en su defensa de dos almas en el hombre. En las siguientes palabras vemos cómo no hay nada fuera de la voluntad que cause el mal o pecado: «Pero ¿cuál puede ser la causa de la voluntad anterior a la misma voluntad? O esta causa es la misma voluntad y entonces en ella tenemos la raíz que buscamos, o no es la voluntad, y en este caso la voluntad no peca. Así, pues, o la voluntad es la primera causa del pecado o la causa primera del pecado está sin pecado; porque no se puede imputar con razón el pecado sino al que peca, y no sé yo a quién se le va a imputar con razón sino al que voluntariamente peca, y por eso no me explico por qué tú te empeñas en buscar esta causa fuera de la voluntad $\rangle^{17}$.

A partir de esta idea, san Agústín dejará bien claro que el mal o pecado no proviene de una naturaleza exterior al alma, en oposición a la tesis maniquea de las dos almas, ni tampoco puede darse en el caso de que la voluntad se encuentre coaccionada. Esta cuestión aparece clara tanto en su debate con Fortunato como en su obra «Las dos almas». Fortunato sostiene la siguiente afirmación: «Porque pecamos sin quererlo y nos vemos forzados por una sustancia enemiga y contraria a nosotros es por lo que alcanzamos la ciencia de las cosas. Advertida por esta ciencia y devuelta a su memoria anterior, el alma reconocerá de dónde trae su origen, el mal en que se halla, con qué obras buenas puede corregir el resultado de su pecado involuntario y obtener para sí el mérito de la reconciliación ante Dios por la enmienda de sus delitos mediante las buenas obras. El autor de ello es Dios nuestro Salvador que nos enseña a practicar el bien y a huir del mal. Me has indicado que el hombre no sirve a la justicia o se somete al pecado por obra de alguna naturaleza contraria, sino espontáneamente. Si no hay ninguna raza contraria, si en el cuerpo no hay más que una sola alma a la que, como afirmas. Dios otorgó el libre albedrío,

16 De lib. arb. II, XVIII, 48. «D'ailleurs, nous donner une volonté capable de faire el mal, n' était-ce pas nous faire un don si dangereux qu'il constitutait à lui seul un mal véritable? Il est très vrai que toute liberté recèle un danger, mais la nôtre n'en est pas moins la condition nécessaire du plus grand des biens qui puissent nous échoir: la béatitude. En soi, la volonté libre ne saurait être un mal; elle n'est pas non plus un bien absolu, comme sont la force, la tempérance ou la justice, dont on ne saurait faire mauvais usage sans le détruire para là même; elle est une sorte de bien moyen, dont la nature est bonne, mais dont 1 éffet peut être mauvais ou bon selon la manière dont l' homme en use», Gilson, E., Introduction a l'étude de Saint Augustin, París, Librairie Philosophique J. Vrin, 1931, pp. 181182.

17 De lib. arb. III, XVII, 49. «Dans tous ces écrits, le problème qui l'obsède est celui de l'origine du mal. La but de l'auteur est de réagir vigoureusement contre le pessimisme et le dualisme des Manichéens. Sans cesse, il répète que nous sommes libres. Nous sommes loin, certes, d'une doctrine déterministe ou fataliste: sa pensée ici est toute impregnée de l'optimisme néo-platonicien et de l'optimisme chrétien. Évidemment, dans cette perspective, la grâce tient assez peu de place. Cependent, même dans cette première période, se reencontré l'affirmation très nette, quoique non developpée, de la realité du péché... Augustin, en pleine réaction anti-manichéenne, porte l'accent sur la $l i$ berté et insiste moins sur la Grâce. Mais son enseignement très explicite sur la liberté est en conexión étroite avec celui sur le péché et en même temps s'ébauche deja sa doctrine de la grâce», Ball, J., «Les développements de la doctrine de la liberté chez Saint Augustin», en L'Année Théologique, 7 (1946), pp. 400-430, La réaction anti-manichéenne (387-397), pp. 405-406. 
estaría sin pecado y no se sometería a él ${ }^{18}$. La réplica de Agustín fue inmediata: «Yo afirmo que no hay pecado si no se peca de propia voluntad. Si hay premio es porque hacemos el bien de propia voluntad... Pero ¿quién dudará de que no se otorga el premio sino a quien ha hecho algo con su buena voluntad? De aquí inferimos también que el castigo se aplica a quien hizo algo con mala voluntad $\rangle^{19}$. Al mismo tiempo que afirma la voluntad libre del hombre como causa del mal o pecado, señala lo absurdo que sería pretender que éste derive de una naturaleza ajena a ella, tal y como lo defendían los maniqueos: «Nadie peca obligado por su naturaleza, ni tampoco por la ajena, porque no pecaría el que se viera obligado hacer por la fuerza lo :que él no quisiera hacer por su propia voluntad... El pecado no consiste en padecer violencia injusta, sino en hacer algo injustamente. Si, pues, ni por su propia naturaleza ni por la ajena se ve nadie obligado a pecar, no resta sino que peque por su propia voluntad» ${ }^{20}$, «Si esa naturaleza contraria que tú (Fortunato) introduces, si esa naturaleza contraria es la totalidad del mal y no hay pecado que no proceda de ella, sólo ella debe merecer el castigo, no el alma de la que no procede el pecado. Y si dices que sólo ella merece el castigo y no el alma, pregunto a quién se ha impuesto la penitencia, a quién se ha mandado arrepentirse. Si el arrepentimiento se le ha ordenado al alma, el pecado procede de ella y ella pecó con su voluntad. Si el alma se ve obligada a cometer el pecado y no es ella la que obró el mal, ¿No es propio de necios y el colmo de la locura que haya pecado la raza de las tinieblas y que tenga que arrepentirme yo de los pecados?» ${ }^{21}$.

La refutación agustiniana de la tesis maniquea de las dos almas es contundente. Pone de manifiesto lo absurdo de dicha propuesta así como su incompatibilidad con el mandato divino que nos exhorta a arrepentirnos de nuestros pecados o males cometidos. Rescata la libertad de la voluntad en un doble sentido, como merecedora de premio por su recta actuación, o como necesitada de castigo por sus pecados. Toda acción, en definitiva, va referida al ser humano, responsable último de su obrar. No cabe en esta postura recurrir a subterfugios que hagan desaparecer la libertad humana, especialmente en sus consecuencias.

Siempre, a lo largo de la historia de la Humanidad, ha estado presente esa tentación de negar la libre voluntad del hombre con el fin de rescatarle especialmente de su responsable culpabilidad, haciendo de factores estructurales, ya sea políticos o económicos, los auténticos causantes de su mal comportamiento. En otros casos, es el inconsciente el que mueve su conduc ta de un modo unidireccional y obsesivo.

A todo ellos se adelantaría Agustín, insistiendo en que: «No se peca si no es voluntariamente» ${ }^{22}$. Y quiere dejar bien claro que: «La voluntad es un movimiento del alma, exento de toda coacción, dirigido a no perder o a conseguir algo $»^{23}$. Ningún alma puede estar a la vez en

18 C. Fort. 20

19 C. Fort. 21

20 De lib. arb. III, XVI, 46. «Augustin avait reconnu le caractère illusiore d'une théorie qui en précipitant toute la nocivité du mal dans la masse physique d'une substance mauvaise prétendait dégager la responsabilité du sujet; mais si tenté qu'il fû́t maintenant de se rallier à l'optimisme platonicien, il ne pouvait (par opposition à la thèse manichéenne) refuser toute realité intrinsèque au mal. Sans doute les Platoniciens se gardaient de nier totalement le mal: la matière, le temps, tout ce qui constitue à des niveaux divers dégradation de l'unité divine, étaient pour eux des aspects, des expressions du mal. Mais c'est précisément ce à quoi Augustin ne pouvait consentir; car, à parler raisonnablement, ni l'imperfection des êtres, ni le monde des corps, ni le temps qui s'écoule ne sont en soi et de par soi «du mal». La mal, c'est autre chose; le mal c'est le peché, et c'est par le biais de la notion religieuse de peché, mais débarrassée des adhérences sordides du manichéisme, quil va a falloir reprender la question. C'est désormais du point de vue des valeurs chrétiennes, a la lumière de la foi révelée, qu'Augustin, en proie lui-même á de graves conflits de coeur et de conscience, va repenser tout le problème de la liberté», Plinval, G., «Aspects du déterminisme et de la liberté dans la doctrine de saint Augustin», en Revue des études augustiniennes, 1 (1955), pp. 345-378, en Solution platonicienne, pp. 347-348.

21 C. Fort. 21

22 De duab. animab. 14

23 Ibid. 
una situación de coacción y libertad respècto a los mismo ${ }^{24}$. Si se le obligara a obrar en contra de su propia naturaleza, es decir, por coacción, ya no se le podría imputar la falta. Hay un ejemplo muy significativo que Agustín trae para ilustrar esta idea: «Entonces les preguntaría: en el caso de una persona de gran fuerza hiciese igualmente algo mal, no con la mano de un sujeto dormido, sino con la de uno bien consciente, pero que, sin embargo, tuviese todos los miembros atados y sujetados, ¿sería responsable de pecado alguno, por el hecho de que lo advertía, aunque sin quererlo en absoluto? Y aquí, extrañados todos de que preguntase tales cosas, sin dudar me responderían que tampoco éste habría pecado en absoluto. ¿por qué es así Porque no puede ser condenado justamente, en el caso de que lo ignorase o no pudiese oponer resistencia, aquel de quien otro se sirvió para hacer algún mal» $»^{25}$.

La realidad del mal o del pecado le lleva a san Agustín a la defensa de la libertad humana. Si se admite el pecado, necesariamente hay que aceptar la voluntad libre del ser humano. La voluntad, definida como un movimiento carente de coacción, es la condición de que exista el pecado, al cual define de la.siguiente manera: «Pecado es la voluntad de retener o conseguir algo que la justicia prohíbe y de lo que hay libertad para abstenerse ${ }^{26}$. Pertrechado con estos presupuestos, Agustín va a proceder a dar el golpe de gracia a las tesis maniqueas, recalcando su falta de congruencia y'de lógica: «Pero si no hay pecado, tampoco hay mal alguno, y si los maniqueos lo afirman dan muerte de un solo golpe a su herejía. Ellos están de acuerdo conmigo en que algunas almas son condenadas por la ley y juicios divinos. Mas si estas almas son buenas, ¿qué justicia es ésa? Si son malas, ¿lo son por naturaleza o por su voluntad? Pero las almas en ningún modo pueden ser malas por naturaleza. ¿Cómo lo probamos? Mediante las definiciones que hemos dado antes de la voluntad y del pecado. En efecto, afirmar que las almas son malas y que no han pecado es el colmo de la demencia; afirmar que pecan sin quererlo es el colmo del delirio, y considerar a alguien como culpable del pecado porque no hizo lo que no pudo hacer es la cima de la maldad y de la locura. Hagan aquellas almas lo que hagan, si lo hacen en virtud de su naturaleza y no por propia voluntad, es decir, si carecen del libre movimiento del alma tanto para hacerlo como para no hacerlo; si finalmente no se les concede poder alguno para abstenerse de su obrar, no podemos admitir pecado en ellas. Ahora bien, todos confiesan que las almas malas son condenadas justamente, e injustamente las que no han pecado. Confiesan, pues, que son malas las que pecaron. Pero aquéllas no pecan, como demuestra la razón; en consecuencia; ese no sé qué género de almas malas que introducen los maniqueos no existe $\rangle^{27}$.

Una vez desmontada la teoría maniquea sobre la libertad, 'Agustín plantea la finalidad auténtica de la libertad. Si somos libres es para realizarnos como personas, para ser felices. Junto a la temática de la libertad, aparece inmediatamente engarzada la de la felicidad. Comprobaremos cómo este engarce es el que aúna, a la vez, a Dios y a su criatura humana. La verdadera libertad es aquella que nos conducirá a la auténtica felicidad y nunca a un remedo de aquella. En esta línea de evolución de su pensamiento se enmarcarán las distinciones que elaborará de la libertad.

El presupuesto del que parte no es otro que el deseo universal de felicidad. Junto con él aparece, al mismo tiempo, la posibilidad de no dar cumplimiento a nuestro deseo: «En cuanto que todos los hombres desean la vida bienaventurada no yerran. El error de cada uno consiste en que, confesando y proclamando que no desea otra cosa que llegar a la felicidad, no sigue, sin embargo, el camino de la vida, que a ella conduce. El error está, pues, en que, si-

24 Ibid.

25 De duab. animab. 13

26 De duab. animab. 15

27 De duab. animab. 17. «Sé también que la mala voluntad radica en hacer aquello que sin su querer no se haría y, que, por eso, la pena justa sigue no a los defectos necesarios, sino a los voluntarios», De civ. Dei XII, VIII. 
guiendo un camino, seguimos aquel que no conduce a donde deseamos llegar. Y cuanto más uno yerra el camino de la vida, tanto menos sabe; porque tanto está más distante de la verdad, en cuya contemplación y posesión consiste el sumo bien. $Y$ es bienaventurado el hombre que ha llegado a conocer y a poseer el sumo bien, lo cual deseamos todos sin género alguno de duda» ${ }^{28}$. Sólo le hará feliz al ser humano, no un bien cualquiera, sino el sumo bien. ${ }^{29}$

Agustín señala dos características importantes del sumo bien. Laprimera es que puede ser poseído y disfrutado por todos los hombres a la vez. A diferencia de los bienes materiales, dificiles de repartir, el bien supremo puede ser compartido por todos a la vez: «Tenemos, pues, en la verdad un tesoro, del que todos gozamos igualmente y en común; ningún sobresalto, ningún defecto menoscaba este gozo. No tiene, no puede tener la verdad amadores envidiosos entre sí; a todos se da igualmente toda... Porque nada de la verdad se convierte nunca en cosa propia de alguno o de varios sino que simultáneamente es toda común a todos». La segunda característica del bien sumo es que, si queremos, podemos conservarlo siempre, sin temor a que nos sea arrebatado como pueden serlo aquellos bienes de fortuna por los que tanto luchamos en esta vida: «Nadie posee con seguridad los bienes que puede perder contra su voluntad. Pero la verdad y la sabiduría (de la que deriva el sumo bien) nadie la puede perder contra su voluntad. Porque nadie puede ser separado de ella por la distancia de lugar, y así, cuando hablamos de separación de la verdad y de la sabiduría, entendemos por esto la perversión de la voluntad, que menosprecia las cosas superiores y ama las inferiores $\rangle^{20}$.

En este mismo sentido se expresaba ya en sus diálogos de Casicíaco, concretamente en el De beata vita. En él aparece claro que el bien supremo para el hombre, que nunca le podrá ser arrebatado, no es otro que el mismo Dios, Verdad, Sabiduría y Bondad: «- ¿Qué debe buscar el hombre para alcanzar su dicha?... ha de ser una cosa permanente y segura, independiente de la suerte, no sujeta a las vicisitudes de la vida. Pues lo pasajero y mortal no podemos poseerlo a nuestro talante, ni al tiempo que nos plazca. Todos hicieron señales de aprobación pero Trigecio dijo: - Hay muchos afortunados que poseen con abundancia y holgura cosas caducas y perecederas, pero muy agradables para esta vida, sin faltarles nada de cuanto pide su deseo. Y el que tiene algún temor - le pregunté yo —, ¿te parece que es feliz? —De ningún modo. - ¿Luego puede vivir exento de temor el que puede perder lo que ama? - No puede -respondió él. - Es así que aquellos bienes de fortuna pueden perderse; luego el que los ama y posee, de ningún modo puede ser dichoso. Se rindió a esta conclusión. Y aquí observó mi madre: - Aún teniendo seguridad de no perder aquellos bienes, con todo, no puede saciarse con ellos, y es tanto más infeliz, cuanto es más indigente en todo tiempo. Yo le respondí: ¿Y qué te parece de uno que abunda y nada en estos bienes, pero ha puesto un límite y raya a sus deseos y vive con templanza y contento con lo que posee? ¿No te parecerá dichoso? -No lo será — respondió ella - por aquellas cosas, sino por la moderación con que disfruta de las mismas. - Muy bien - dije yo-; ni mi interrogación admite otra respuesta ni tú debiste contestar de otro modo. Concluyamos, pues, que quien desea ser feliz debe procurarse bienes permanentes, que no le puedan ser arrebatados por ningún revés de fortuna. - Ya hace rato que estamos en posesión de esa verdad - dijo Trigecio. - ¿Dios os parece eterno y siempre permanente? - Tan cierto es eso —observó Licencio- que no merece ni preguntarse ${ }^{3 !}$.

El texto es largo pero ha valido la pena traerlo a colación. Queda así perfilada cuál ha de ser la dinámica de la verdadera libertad: la consecución del bien supremo que es Dios. Si se aparta de este camino no sólo no lo conseguirá sino que vivirá una vida desgraciada e infeliz:

28 De lib. arb. II, IX, 26

29 De lib. arb. II, XIV, 37

30 Ibid.

31 De beata vita II 11 
«En esto consiste también nuestra libertad, en someternos a esta verdad suprema; y esta libertad es nuestro mismo Dios, que nos libra de la muerte, es decir, del estado de pecado ${ }^{32}$.

Aquí va a empezar la siguiente andadura agustiniana. Necesitamos de la ayuda de Dios para ser libres y felices, para alcanzar el sumo bien. Desde esta postura y reconociendo el deterioro de la imagen de Dios de la que somos portadores, hablará de la necesidad de la gracia divina, polemizando con los pelagianos que atribuyen al ser humano una libertad totalmente autónoma y que no necesita de la ayuda de Dios para reảlizar el bien y por lo tanto para salvarse. He aquí el nudo gorgiano que habrá de desenredar para que la libertad cristiana brille en toda su autenticidad. En este nuevo camino especulativo, lejos de negar la libertad, Agustín la seguirá afirmando pero siendo ya conscientes de sus profundas deficiencias y del papel de Dios en su propia liberación. Es un planteamiento teísta de la libertad en clara confrontación a una concepción atea de la misma.

\section{El debate con los pelagianos}

En esta nueva etapa, san Agustín nos presenta una perspectiva diferente sobre la libertad. Lejos de ser una nueva concepción de la misma, nos ofrece una idea de la libertad humana mucho más acorde con la doctrina cristiana, que lejos de negarla, es consciente de sus límites y de la necesidad de la ayuda divina para la ejecución del bien, su verdadero objetivo.

Es ahora, en su polémica con los pelagianos, cuando podemos captar la auténtica esencia de la libertad agustiniana que reconoce tanto su capacidad como sus limitaciones. Muchas de sus afirmaciones podrán hoy chocarnos, acostumbrados como estamos, a poner la esencia de la libertad en la elección, sea del bien o del mal, pero a la postre tendremos una idea más profunda de la misma y, con ella, del ser humano. No hay que olvidar que la libertad es una de las características más importantes y definitorias del hombre.

No obstante, para poder situarnos mejor en el contexto, vamos a presentar a continuación las tesis pelagianas más importantes a las que hubo de rebatir san Agustín, tanto para defender la doctrina cristiana verdadera como para transmitirnos el estado en el que se encuentra nuestra libertad y la necesidad que tiene no sólo de ser liberada sino apoyada para lograr sus objetivos. El primero y fundamental: su realización personal, su felicidad que de nuevo sólo puede estar en la conquista y posesión de Dios, Bien Sumo. Vemos así que en lo fundamental nada ha cambiado pero sí hay una mayor comprensión del estado en el que se encuentra nuestra libertad así como de sus potencialidades.

El investigador Portalié cuando habla de la idea principal del sistema pelagiano afirma que: «A. Elle n'est pas uniquement dans la négation de l'ordre surnaturel; pour beaucoup, le pélagianisme est un naturalisme excluant l'élevation surnaturelle, l'adoption divine, la chute, tout mérite d'un ordre supérieur, mais admettant que la volonté dépend du gouvernement divin. De là cette règle solennelle d'interprétation: toutes les fois qu'Augustin exige une grâce contra Pélage, il s'agit d'un acte surnaturel. Or, cette vue et cette règle sont incomplètes: sans doute Pélage a nié toute grâce surnaturelle, quoi qu'un aient dit les jansénistes; il admettait seulement les dons extérieurs de la révélation, de la loi, des exemples du Christ... Mais Pélage a nié plus que cela; même en dehors de l'ordre surnaturel, il a exageré les forces de la liberté... B. le fond du système pélagien est donc 1 índépendance absolue de la liberté par rapport à Dieu, et sa puissance illimitée pour le bien comme pour le mal» ${ }^{33}$. Resumiendo, podemos decir que para Pelagio, la libertad humana no sólo no necesita de la ayuda de Dios, es decir de la gracia,

32 De lib. arb. II, XIII, 37

33 Vacant, A., y Mangenot, E., Dictionnaire de Théologie Catholique, París, Letouzey et Ané Éditeurs, 1903, Portalié, E., Augustin (Saint), p. 2381. 
para hacer el bien sino que tiene una capacidad propia para realizarlo, del mismo modo que puede elegir y hacer el mal. En definitiva, la libertad humana es todopoderosa y no está dañada desde su origen. Desde esta teoría, que Portalié califica de naturalismo, cae todo el entramado sobrenatural del Cristianismo y en definitiva el propio Dios como liberador del hombre.

En palabras de E. Gilson: «La doctrine de Pélage, défend le péché comme n'étant qu'un mauvais usage du libre arbitre; il ne diminue ni sa liberté, ni sa bonté naturelle, ni par conséquent son pouvoir de faire le bien. S'il en est ainsi, le secours de la grâce n 'a pas à porter sur la volonté elle-mème qui, n étant pas corrompue, n'en pas besoin; il se reduit par conséquent au pardon de l'offense faite à Dieu par l'accomplissement de l'acte mauvais. Dieu n'acorde pas la gràce de bien faire à une volonté devenue impuissante, il fait gràce comme un juge qui pardonne et remet la faute commise. De là une transformation profonde dans l'économie genérale du dogme de la rédemption ${ }^{34}$. El autor afirma con respecto a Pelagio y al pelagianismo, que la libertad humana no se encuentra disminuida ni corrompida por ningún pecado y que por sí sola puede hacer el bien. La gracia o la presencia de Dios se reduce a la de un juez que perdona la falta cometida.

El planteamiento antropológico de san Agustín está en el polo opuesto del pelagianismo. Para entenderlo, y a la vez ir perfilando su polémica contra las tesis pelagianas, no nos queda otra opción que partir de su temática, el hombre imagen de Dios. A través de ella veremos cómo el hombre es imagen de Dios y a la vez nos percataremos de cómo esa imagen quedó deteriorada por el pecado de los primeros padres y por los nuestros propios. Como consecuencia, el ser humano es incapaz de llevar a cabo actos buenos y válidos para su salvación. La renovación de la imagen divina vendrá tanto de la mano de la gracia divina como de nuestra propia libertad. Ambas a una conseguirán la perfección, felicidad y salvación del hombre.

Agustín tendrá las Sagradas Escrituras siempre presentes en sus escritos. De ellas extrajo siempre la sabia que fecundaría toda su especulación filosófica y teológica. La tesis clave sobre la que gravita toda su antropología no es otra que la afirmación que hace la Biblia al decir que el hombre ha sido hecho a imagen y semejanza de Dios: «Y dijo Dios, hagamos al hombre a nuestra imagen y semejanza. En esta obra de Dios debe notarse una cierta unión y separación de los otros vivientes pues dice que fue hecho el hombre en el mismo día que las bestias y que igualmente todos son animales terrestres; pero, sin embargo, por la excelencia de la razón según la cual el hombre es hecho a imagen y semejanza de Dios, separadamente se habla del hombre, después que según costumbre ha terminado la formación de otros animales diciendo: y vio que era bueno» ${ }^{35}$.

La creación del hombre a imagen y semejanza de Dios, le otorga un puesto especialísimo en el mundo, tanto con respecto a los seres inertes como a los vivos, como es el caso de los animales: «Aquí tampoco debemos de pasar en silencio lo que al decir nuestra imagen se añadió inmediatamente: y tenga dominio sobre los peces del mar y los volátiles del cielo y sobre los demás animales que carecen de razón. Se dijo esto para que entendiésemos que el hombre fue hecho a imagen de Dios en lo que aventaja a los animales irracionales, es decir, en cuanto a la razón o la mente o la inteligencia o como queramos llamarla, si existe alguna que otra palabra más apta» ${ }^{36}$.

34 Gilson, E., Introduction a l'Étude de Saint Augustin, op. cit. p. 199. Cfr., Brown, P., Agustin, Pelagio y el Pelagianismo, pp. 354-366.

35 De Gen. ad litt. imp. XVI, 55; Cfr., De doct. christ. I, XXII

36 De Gen. ad litt. III, XX. Es cierto que Dios en el día sexto hizo al hombre a su imagen y semejanza; y también allí se dijo: Varón y mujer los hizo (Gen. I, 27). Hemos visto que la primera de estas dos frases debe entenderse del alma mientras que la segunda, donde se distinguen los sexos, la debemos tomar como dicha en relación a los cuerpos», De Gen. ad litt. X, II,3 
El ser humano ya no lleva en sí un vestigio de lo divino sino una especial marca de Dios que se traduce en ser su imagen, su obra más lograda a la que le exigirá un acercamiento y una -progresiva divinización, lo que llamaría Plotino, una vuelta al Uno, contando con su libertad.

A partir de aquí nos podemos hacer la siguiente pregunta: ¿En qué estado se encuentra ahora la imagen de Dios en el hombre?: La respuesta de san Agustín es taxativa, se encuentra deteriorada, deformada por el pecado. En primer lugar por el pecado original cometido libremente por los primeros hombres y transmitido a toda la humanidad y en segundo lugar por los :posteriores y consiguientes pecados cometidos también libremente por los hombres que desfiguran la huella de Dios en el ser humano. Sin embargo no se ha perdido completamente. Su renovación y acercamiento a Dios es todavía posible. Queda un resto que nos identifica con lo divino pero que hay que curar, mejorar y elevar. Para ello no sólo se requerirá el esfuerzo de la libertad sino también, y de modo muy especial, la gracia de Dios. La tesis clave que defiende san Agustín en sintonía con la doctrina cristiana es la siguiente: la libertad humana, por hallarse en un estado de postración al ser un ingrediente decisivo de la imagen divina en el hombre, no puede llevar a cabo su cometido por sí sola, es decir, no puede realizar ni alcanzar el Bien sin el apoyo de Dios. Por consiguiente, abandonada a sus fuerzas, no sólo no llegará a poseer el Bien y por lo tanto la felicidad sino que nunca podrá liberarse de las cadenas que la atenazan. No hay cabida a una liberación humana sin la participación de Dios. No hay libertad verdadera sin Dios. Todo este planteamiento exigirá clarificar la concepción agustiniana de la libertad y lo haremos teniendo en cuenta la polémica que llevó a cabo con los pelagianos. El nuevo trasfondo queda así perfilado: su disputa con el pelagianismo. Pasemos a ver algunos textos: «Porque, después que el hombre, elevado a honor delinquió, se asemejó a las bestias y engendrado como ellas, conservándose siempre en él una centellica de razón que hace aparecer la imagen de Dios en él» ${ }^{37}$; «No obstante como la imagen de Dios en el alma no está destruida por la mancha de los aspectos terrenos hasta el punto de no haber quedado en ella algunos vestigios aunque lejanos y débiles ${ }^{38}$. Estos afirmaciones de Agustín nos demuestran que para él el hombre, a pesar del pecado, conserva una semejanza con Dios que es preciso restaurar para que de nuevo reluzca en toda su plenitud. Para conseguirlo, como hemos dicho con anterioridad, se necesita de la gracia de Dios: «Pues por el pecado del primer hombre, el cual procedió de su libre albedrío, fue viciada y condenada la naturaleza misma, a la cual sólo rehabilita la gracia divina por el Mediador de Dios y de los hombres y Médico Omnipotente $\rangle^{39}$.

¿Cuál es la concepción más completa que de la libertad nos dejó Agustín? La respuesta a esta pregunta conlleva además la réplica a las tesis pelagianas. Por ello es tan importante que nos adentremos en la auténtica y definitivá comprensión que de la libertad nos ha dejado.

Cuando nos disponemos a hablar sobre la libertad, partimos en general de una idea que casi se ha convertido en un axioma: la consideramos como la capacidad de elección, y en el ámbito moral, esa elección se lleva a cabo entre el bien y el mal. Sin embargo esta forma tan aceptada de entender la libertad no es la que propone san Agustín. Va más allá y, para él, sólo hay auténtica libertad cuando ésta elige el bien. Seguro que esta afirmación chocaría en un debate corriente sobre la libertad pero para poder entenderla es preciso que nos adentremos un poco más en san Agustín y en su polémica con los pelagianos.

Para desarrollar esta cuestión nos basaremos tanto en los textos agustinianos como en los estudios realizados al respecto por varios investigadores, entre ellos, los llevados a cabo por el profesor Juan Pegueroles. En su artículo: «La libertad para el Bien en San Agustin», sostiene

37 De civ. Dei XXII, XXIV,2

38 De spiritu et litera XXVIII, 48

39 De gratia Christi, I, L, 55; Cfr., Dolby Múgica, C., El hombre es imagen de Dios. Visión antropológica de San Agustín, Pamplona, Eunsa, 2002; Dolby Múgica, C., «El hombre como imagen de Dios en la especulación agustiniana», en Augustinus 34 (1989), pp. 119-154. 
lo siguiente: «El concepto de la libertad, en San Agustín, comporta dos elementos: autodeterminación de la voluntad y orientación al bien. La orientación al bien puede ser doble: al bien como bien-para-mí o felicidad, y al bien como bien-en sí o moralidad. El fin último y el bien supremo al que tiende el hombre es Dios, el cual es a la vez orden (bien-en-sí) y paz (bien-paramí). Autodeterminación de la voluntad equivale a voluntario. Autodeterminación más orientación al bien como bien-para-mí es liberum arbitrium. Autodeterminación más orientación al bien como bien-para-mí y como bien-en-sí es libertas» ${ }^{40}$.

Aquí están señaladas las dos consideraciones que Agustín hace de la libertad: la libertad como libre albedrío que busca la felicidad propia, la plenitud humana y la libertad como tal que no sólo busca el bien para sí sino el Bien en sí mismo. En última instancia, es la que busca a Dios como encarnación del Bien y como el único que puede hacer feliz y libre al hombre. Una vez más, constataremos desde esta perspectiva, cómo la libertad agustiniana está indiscutiblemente unida a Dios.

En primer lugar vamos a reflexionar sobre la libertad como libre albedrío y luego lo haremos sobre la libertad como tal. El detenernos aquí, no implica alejarnos de la polémica antipelagiana. Todo lo contrario. Se trata de la única forma de entenderla así como de comprender los verdaderos motivos que tuvo Agustín para rechazar las tesis pelagianas

¿En qué consiste el liberum arbitrium? En la búsqueda por parte del ser humano del bien propio. El libre albedrío se manifiesta en el deseo natural de felicidad que tiene todo hombre. Una verdad que no necesita demostración y que es aceptada sin discusión por todos tal y como se presentó en los diálogos de Casicíaco «¿Todos queremos ser felices? Apenas había dicho esto, lo aprobaron unánimemente $)^{41}$. En la misma línea se expresa en su Réplica a Juliano, obra incompleta: «¿Qué rechaza la naturaleza? El dolor. ¿Qué apetece? La felicidad. Finalmente, si consultamos a nuestro libre albedrío sobre esto, vemos que nada hay más enraizado en nuestra naturaleza, pues, a pesar de nuestras miserias, persiste siempre en nosotros el deseo de evitar la desgracia y querer ser felices. Y es esto tan verdad, que los mismos que por su mal vivir son miserables y quieren vivir mal, no quieren, sin embargo, ser desgraciados sino felices. Y no se trata del libre albedrio, que nos hace querer el bien en nuestras acciones, pues éste lo hemos perdido por el pecado y recuperado por la gracia; sino que hablo del libre albedrío que desea nuestra felicidad y no queremos ser desgraciados; y este deseo ni miserables ni dichosos lo pueden perder. Sin excepción, todos queremos ser felices; verdad tan incuestionable que ni los filósofos de este siglo, incluso los académicos, que dudan de todo, si creemos al jefe

40 Pegueroles, J., «La libertad para el Bien en San Agustín», en Espiritu, 23 (1974), pp. 101-106, p. 101. «Agustín distingue, pues, dos clases de libertad. De una dice que es la «gran libertad», que lleva consigo «una voluntad libre y grande facilidad de vivir según el bien», que es un don de la gracia de Dios, y que no existe en el hombre cautivo del pecado. De la otra afirma que se basta para obrar el mal, pero que es débil e insuficiente para obrar el bien, que «sus fuerzas fueron grandes en el momento de la creación del hombre, mas las perdió pecando», que es un don natural de Dios en virtud de la creación, y que no se pierde por el pecado... Creo yo, que el lenguaje y las ideas que utiliza el Hiponense para referirse a una y otra libertad autorizan a denominar libertas minor al libre albedrio o libertad de elección en el pecador y libertas mayor a la verdadera y auténtica libertad de que goza el hombre justo ayudado por la gracia, y también el hombre anterior a la caída original y, más aún, el bienaventurado» en Galindo Rodrigo, J. A., «La libertad como autodeterminación en San Agustín», en Augustinus, 35 (1990), pp. 299. 320, en pp.303-304. Cfr., Galindo Rodrigo, J. A., «Libertad y libra albedrío en San Agustín», en Augustinus, 31 (1986), pp. 343-355. En el mismo sentido se expresa Mary T. Clark: «Such was the Augustinian experience which grounded Augustine' distinctive theory of freedom which is based upon a clear distinction between free choice and fredom. He defined free choise as an ability to do evil, a capacity to do good; he defined freedom as the ability to do good by the rigth us of free choice, the exercise of a good will. Free choise is natural to man and never lost; freedom is acquired and can be lost... This Augustinian distinction between free choise which Augustine uses as a synonym for free will and which is found in all men, and freedom or libertas which is synonimous with the good will and is the fruit of the grace of God and the effort of man... «Augustinian freedom», en Augustinus 39 (1994), pp. 123-129, en p. 125 .

41 De beata vita, II, 10 
Tulio, se ven forzados a confesar, diciendo que es la única verdad sin margen para la duda y deseada por todos. Pero este libre albedrío encuentra su fuerza en la gracia de Dios; lo que naturalmente deseamos, es decir, la felicidad, la podemos conseguir con una vida sana ${ }^{42}$.

Se trata de un texto muy esclarecedor. El libre albedrío es el deseo de felicidad que todos llevamos como anhelo impreso en nuestra alma pero que no todos alcanzan. Para ser felices tendríamos que hacer el bien y es esto lo que el libre albedrío no puede conseguir por sí solo. Necesita de la gracia de Dios. Agustín nunca defendió la pérdida del libre albedrío sino que dejo clara su incapacidad para hacer el bien sin la ayuda de Dios, como consecuencia del pecado. Es en este punto donde comienza la polémica con los pelagianos incluso varios años antes de materializarse. Así lo explica el estudioso Joseph Ball a propósito de la Carta a Simpliciano: «A dater de 397 c'est une nouvelle période qui commence; celle de la connaissance exacte et précise du rôle de la Grâce... Augustin commentant saint Paul, insiste sur la radicale impuissance de 1 'homme pécheur sans la' grâce. $A u n^{\circ} 9$, voici une de de ses penseés les plus chères: notre volonté, sans la grâce reste libre pour l'accomplissement du mal; elle désire le bien, mais est frappée d'impuissance pour le réaliser. La nature, infectée par le peché originel et viciée par les mauvais habitudes, est esclave de la concupiscence. Malgré tout, -l'evêque d'Hippone le précise bien au $\mathrm{n}^{\circ} 11-$, le libre-arbitre humain subsiste: «Je trouve en moi, dit saint Paul (Rom., VII,18), la volonté de faire le bien, mais je ne trouve pas le moyen de 1 áccomplir»... Il est certain que la volonté est en notre pouvoir, puiqu'elle est en nous, mais si elle n'a pas la force d'accomplir le bien, c'est une punition du péché originel. Telle n'était pas au début la première nature de 1 'homme!» ${ }^{43}$.

En la Réplica a Juliano, obra inacabada, san Agustín deja claras estas mismas ideas, rechazando la concepción pelagiana que no acepta la naturaleza humana deformada por el pecado y por consiguiente que no ve cómo éste ha incidido en el propio libre albedrío: «Si quieres saber cuándo y dónde se concede al hombre el no poder pecar, busca en la recompensa que después de esta vida recibirán los santos. Esto si no crees que por la malicia del pecado ha perdido el hombre el libre albedrío, del que podía servirse para hacer el bien. Escucha al que dice: No hago el bien que quiero, sino el mal que aborrezco. Pero vosotros no queréis que este mal venga de una fuente viciada, sino de una mala costumbre avasalladora, $\mathrm{y}$, en consecuencia, confesáis que el libre albedrío perece sólo por su mal uso. Y no admitís que este gran pecado, más enorme que toda mala costumbre, haya podido viciar el libre albedrio en la naturaleza humana, como si sólo una mala costumbre pudiera viciar al hombre y le hiciera decir que quiere el bien, sin poderlo realizar. Existe una libertad dada al hombre que permanece siempre en la naturaleza, y es esta voluntad la que nos hace querer ser felices y no podemos no quererlo. Pero esto no basta para ser feliz, pues no nace el hombre con esta libertad inmutable del querer, por

42 C. Iul. Op. Imp. VI, 26. El deseo de felicidad es justamente el recuerdo de Dios. Así lo escribe la filósofa Hannah Arendt que empezó su andadura filosófica con el estudio del filósofo: «Y en ello consiste la dependencia del ser creado respecto del Creador. Que el hombre en su deseo de ser feliz dependa de una noción de felicidad que nunca pudo experimentar en su vida terrena, y que tal noción tenga además que ser la única instancia determinante de su conducta terrena, sólo puede significar que la existencia humana como tal depende de algo externo a la condición humana que nosotros conocemos y experimentamos. Y como quiera que el concepto de felicidad está en nosotros merced a una conciencia que se equipara a la memoria (o sea, como quiera que la felicidad no es idea «innata» sino idea recordada), esto (externo a la condición humana» significa de hecho algo anterior a la existencia humana. El Creador es, en efecto, ambas cosas: anterior al hombre y externo al hombre. El Creador está en el hombre sólo en virtud de la memoria del hombre, que le mueve a desear la felicidad y con ella una existencia que dure por siempre: «Pues yo no sería, mi Dios, no existiría en absoluto, si Tú no estuvieras en mí» (Confesiones, I, II, 2), es decir, si no estuvieras en mi memoria», Arendt, H., El concepto de amor en san Agustín, Madrid, Encuentro, 2001, p. 76. Edición inglesa: Love and saint Augustine, Chicago \& London, The University of Chicago, 1996.

43 Ball, J., «Les développements de la doctrine de la liberté chez Saint Augustin», en $L$ 'Année théologique, 7 (1946), pp. 400-430, en p. 405. 
el cual pueda y quiera hacer el bien; así como es en él innato el deseo de felicidad; bien que todos ansían incluso los que no quieren vivir bien ${ }^{44}$

Estas afirmaciones sobre el libre albedrío y su incapacidad de hacer el bien son las que nos harán comprender la interpretación que hace Agustín de la libertas o auténtica libertad que es capaz de realizar el bien pero con la ayuda de la gracia: «Para que se dé libertad verdadera o libertas, se requiere además del liberum arbitrium, una segunda orientación de la voluntad al bien como bien-en-sí: libertas qua bene vivere volumus. Esta segunda voluntad del fin como bien-en-sí no es necesaria pero ha de llegar a serlo. En el origen, al hombre, tal como fue creado, le era tan natural y necesario querer bene vivere como lo es ahora querer beate vivere. Pero la imagen de Dios en el hombre fue deformada por el pecado. Sólo le quedó al hombre la tendencia natural a Dios como bien-para-mí... Con este resto de la imagen primera que es la tendencia a Dios como felicidad, y con la gracia de Cristo puede el hombre reformarse y hacer otra vez natural y necesaria la orientación a Dios como bien-en-sí $\rangle^{45}$.

Los pelagianos defienden la posibilidad de conseguir la libertas por el propio esfuerzo de la libertad humana y no son conscientes del grave deterioro que el pecado causó en la imagen de Dios de la que somos portadores así como en uno de sus principales aspectos: el libre albedrío. Niegan en definitiva la necesidad de la gracia para restituir aquella primigenia imagen de Dios en nosotros y se consideran capaces de llevarla a cabo por ellos mismos: «Defendiendo el libre albedrío, lo precipitan queriendo que para obrar el bien estribemos en él más que en la ayuda del Señor. Pero ¿quién entre nosotros dice que por el pecado del primer hombre pereció el libre albedrío en el género humano? Pereció, sí, la libertad a causa del pecado; pero fue la libertad que existió en el paraíso de poseer plena justicia junto con la inmortalidad; por lo que la naturaleza humana necesita de la divina gracia, según lo que dice el Señor: Si el Hijo os diere libertad, seréis realmente libres. Tan es así que el libre albedrío no pereció en el pecador, que precisamente por el libre albedrío pecan sobre todo los que pecan con deleite $\mathrm{y}$, amando el pecado, escogen lo que les agrada. Por eso dice el Apóstol: Cuando erais esclavos del pecado, erais libres respecto de la justicia. En lo cual se muestra que ni al mismo pecado pudieron servir sino con otro género de libertad. No están, por tanto, libres de la justicia sino por la gracia del Salvador» ${ }^{46}$. En el mismo sentido escribe: «La verdadera libertad consiste en la alegría del bien obrar, y es también piadosa servidumbre por la obediencia a la ley. Pero ¿de dónde le vendrá al hombre, enajenado y vendido, esta libertad, sino por el rescate de aquel que dijo: Si el Hijo os librare, seréis verdaderamente libres?» ${ }^{47}$.

De estas afirmaciones cabe resaltar que la verdadera libertad en san Agustín no consiste en la posibilidad de elegir entre el bien o el mal sino que hay que ir más allá del libre albedrío para conseguir un grado mayor de libertad que se encuentra en la necesidad de hacer el bien. ${ }^{48}$

\section{C. Iul. Op. Imp. VI, 12}

45 Pegueroles, J., art. cit., pp. 104-105. Cfr., Pegueroles, J., «Libertad y necesidad, libertad y amor, en San Agustín», en Espiritu, 32 (1983), pp.109-1 14. Fitzgerald, A.D., Diccionario de San Agustín, Burgos, Monte Carmelo, 2001 , consultar el término «Libertad», concretamente, «Verdadera libertad», pp. 808-809.

$46^{\prime}$ Contra duas epistolas pelagianorum I, II, 5; «Se ha de confesar, pues, que poseemos el libre albedrio para el bien y para el mal; mas para hacer el mal, uno se aparta de la justicia y sirve al pecado, mientras nadie es libre para hacer el bien, sino es libertado por el que dijo: Si el Hijo de Dios os librare, entonces seréis verdaderamente libres», De corrept. et gratia II,2

47 Enchir. XXX,9. «Cependant, elle (la volonté) n'est pas radicalement viciée. A y regarder de plus près, on trouve encore dans l'homme déchu quelques vestiges de bien. Il n'est pas complètement corrompu. Il conserve toujours et malgré tout son libre arbitre! Il desire, il veut, il est capable de vouloir encore le bien. Mais sa volonté est faible et anémiée: elle n'a plus la force de le réaliser! «Pour tomber, l'homme n’a eu qu' à le vouloir, mais il ne suffit pas de vouloir se relever pour le pouvoir!» (Retract. I, 9,6). La volonté débilitée n'est pas radicalement mauvaise, mais radicalement impuissante» en Ball, J., «Libre arbitre et liberté dans S. Augustin», en $L$ 'Année théologique, 6 (1945), pp. 368-382, en p. 374. 
Este punto lo ha visto muy bien el profesor Pegueroles al estudiar el diálogo que sostuvo Agustín con Juliano a propósito de la definición de la libertad en su Réplica a Juliano, obra incompleta: «(Libros I-II.) Juliano empieza dando su definición de libertad: «Libertas arbitrii... in admittendi peccati et abstinendi a peccato posibilitate consistit» (78). Libertad es posibili$d a d$ : poder hacer el bien o el mal. Un poco más adelante añade: la posibilidad del bien y del mal es buena. «Et boni possibilitas et mali bona est. Quoniam posse bonum facere aula virtutis est; posse malum facere testimonium libertatis est» (81). San Agustín responde: entonces Dios no sería libre, porque, como admite el mismo Juliano, Dios sólo puede ser justo. «Non est ergo liber Deus... de quo etiam ipse divisti: Deus esse nisi iustus non potest» (81).

En segundo lugar, San Agustín asienta que el hombre, sin la gracia, sólo puede hacer el mal. No tiene posibilidad (del bien y del mal), sino necesidad (del mal). Sólo la gracia le libera de esta necesidad (o esclavitud). «Nunc (homo) in ruina sua liber est iustitiae servusque peccati; nec potest servus esse iustitiae et liber a dominante peccato nisi eum Filius liberaverit» (82). Libertas es liberación: «Hoc si intelligatis non aliud intelligetis esse arbitrium laudabiliter liberum nisi quod fuerit Dei gratia liberatum» (79)... Juliano exclama: ¡es absurdo! Si sólo puede hacer el mal, el hombre no es libre: «Liberum vocas quod dicis nisi unum velle non posse» (100)... San Agustín responde: todo depende del punto de partida. Si se define la libertad como posibilidad, tiene razón Juliano. Pero la libertad no puede consistir en la posibilidad, porque entonces Dios no sería libre: «Si liberum non est nisi quod duo potest velle, id est, et bonum et malum, liber non est Deus, qui malum non potest velle» (101). Juliano insiste: si el hombre sólo puede hacer el mal, su voluntad no es libre, porque esta coaccionada al mal: «Quomodo dicebatur voluntas libera si malum velle tantummodo cogebatur?» (101). La respuesta de San Agustín es profunda y categórica. La voluntad nunca quiere coaccionada: si enim cogitur, non vult (101). La voluntad nunca quiere sin querer: sería absurdo. «Quid absurdus quam ut dicatur (voluntas) nolens velle quod bonum est?» (101). La voluntad, tanto si quiere el mal sin poder querer el bien, como si quiere el bien sin poder querer el mal, es libre, porque en ningún caso quiere sin querer. «De natura Dei, vide quid sentias, homo qui dicis cogi hominem ut bonum velit, si mallum velle non possit. Numquid enim Deus cogitur velle bonum, quia velle non potest malum?» $(101) »^{49}$.

De estos comentarios a los textos agustinianos podemos sacar las siguientes conclusiones: la auténtica libertad no es posibilidad del bien o del mal sino necesidad del bien. Cuando se habla de necesidad, Agustín hace referencia a una necesidad no coaccionada sino querida del bien. Del mismo modo que por el libre albedrío queremos de modo necesario ser libres, cuando obtengamos la verdadera libertad, cuando empecemos a ser realmente libres, querremos también de modo necesario el bien ${ }^{50}$.

48 «En los textos agustinianos sobre el libre albedrío y la libertad se manifiesta patentemente una positiva articulación entre uno y otra. Puesto que el mismo libre albedrío se convierte, mejor, es libertad cuando realiza el bien por la acción liberadora de la gracia... La opción por el bien eleva al libre albedrio a la categoría de auténtica libertad», en Galindo Rodrigo, J. A., «La libertad como autodeterminación en san). Agustín», en Augustinus, 35 (1990), pp. 299-320, en p. 306.

49 Pegueroles, Juan, «Libertad como posibilidad, libertad como necesidad. Juliano y San Agustín», en Espíritu 36 (1987), pp. 109-124, en pp. 110-111. «El acto voluntario, para ser tal acto voluntario, no supone ni el libre albedrío, ni la liberación producida por la gracia. Basta con que el acto no se vea coaccionado del exterior: libertas a coactione, non libertas a necesitate», Vergez, A., «San Agustín y la Filosofia Cristiana. El problema de la culpa y de la libertad», en Augustinus, 19 (1974), pp. 3-19, en p. 16.

50 «La necesidad del bien (el amor necesario del bien) no suprime la libertad. El bien arrastra (necesidad) a la voluntad sin violentarla, porque es su fin. Al pasar de la posibilidad del bien a la necesidad del bien, la libertad se perfecciona, como todo lo que pasa de la potencia al acto. San Agustín se opone a Juliano (y a Pelagio): sin la gracia, no hay en la voluntad posibilidad del bien, sino imposibilidad del bien o necesidad del mal (non posse non peccare). San Agustín se opone (por adelantado) a Jansenio (y a Lutero): con la gracia, no hay en el hombre 
La perfección de la libertad se manifiesta en el paso entre el liberum arbitrium y la $l i$ bertas: «La libertad como necesidad (del bien), es el fin de la libertad como posibilidad (del bien). En el sentido doble de la palabra fin: como destino, telos: lo que todavía no es, lo que ha de llegar a ser; y como final: lo que ya no es» ${ }^{51}$. El hombre se hará cada vez más libre cuan: to más prendado esté del bien y cuanto más fuerte sea su adhesión al mismo. La necesidad del bien en su libre actuación es fruto de la gracia de Dios a la que secunda la voluntad libre. En : esta vida siempre está la posibilidad de caer en el mal, en el pecado y por lo tanto en lainfelicidad. Sólo en la otra vida tendremos garantizada nuestra total permanencia en el bien y como consecuencia de ello, tendremos asegurada nuestra felicidad ${ }^{52}$. He aquí un bello texto agustiniano de La Ciudad de Dios, en el que Agustín sintetiza de modo brillante la trayectoria de la libertad cristiana: «El primer libre albedrío que se dio al hombre cuando Dios lo creó recto, consistía en poder no pecar; pero podía también pecar. El último será superior a aquél y consistirá en no poder pecar. Y éste será también don de Dios, no posibilidad de su naturaleza. Porque una cosa es ser Dios, y otra, ser particionero de Dios. Dios, por naturaleza, no puede pecar; en cambio, el que participa de Dios, sólo recibe de Él la gracia de no poder pecar. Guardar esta gradación es propio del don divino: dar primero un libre albedrío por el que el hombre pudiera no pecar y, al fin, otro por el que no pudiera pecar. El primero permitía la adquisición de méritos, y el último, la recepción de premios. Mas porque esta naturaleza pecó cuando podía pecar, es librada por una gracia más liberal para llegar a la libertad en que no pueda pecar. Así como la primera inmortalidad, que Adán perdió pecando, consistió en poder no morir, y la última consistirá en no poder morir, así el primer libre albedrío consistió en poder no pecar, y el último consistirá en no poder pecar. Y la voluntad de piedad y de equidad será tan inamisible como la felicidad. Es cierto que al pecar no conservamos ni la piedad ni la felicidad; empero, el querer la felicidad no lo perdimos ni cuando perdimos la felicidad. ¿Hemos de negar a Dios libre albedrío porque no puede pecar? Todos los miembros de la Ciudad santa tendrán una voluntad libre, exenta de todo mal y llena de todo bien, gozando indeficientemente de la jocundidad de los goces eternos, olvidada de las culpas y de las penas, pero sin olvidarse de su liberación para no ser ingrata con su Libertador» ${ }^{53}$.

\section{CONCLUSIONES FINALES}

Hemos podido seguir, a lo largo de este trabajo, la trayectoria agustiniana de la libertad. En primer lugar su descubrimiento y defensa frente a las tesis maniqueas. La libertad es la causante del mal o pecado pero al mismo tiempo es un bien que Dios ha dado al ser humano para que con ella sea capaz de adquirir méritos y recibir premios. En segundo lugar, y frente a los pelagianos, san Agustín mantiene la absoluta necesidad de la gracia o ayuda divina para que la libertad humana, deteriorada en su origen por el pecado, sea capaz de hacer el bien y de encaminarse a su liberación. En otras palabras, para que el hombre logre una libertad que sea ne-

necesidad del bien, (non posse peccare), sino sólo la posibilidad del bien. Con esta posibilidad el hombre puede merecer la necesidad (progresivamente mayor) del bien (que sólo se dará perfectamente en el cielo)», Pegueroles, J, «Postcriptum. La libertad como necesidad del bien, en San Agustín», en Espiritu, 37 (1988), pp.153-156, en p. 154.

51 Pegueroles, J., «Libertas, fin del liberum arbitrium en San Agustín. Segundo postcriptum», en Augustinus, 39 (1994), pp. $365-371$, en p. 365.

52 «La inalterabilidad de la voluntad libre en el bien es una condición indispensable para gozar de la plena felicidad; porque la posibilidad de caer en el mal es equivalente a la pérdida de esa felicidad; ya que ésta, si ha de ser perfecta, exige la total seguridad de la misma. Por eso, la necesidad de evitar el mal por parte de la libre voluntad se nos muestra como digna del máximo deseo por ser igual a la plena felicidad», Galindo Rodrigo, J. A, «La libertad como autodeterminación en san Agustín», en Augustinus, 35 (1990), pp. 299-320, en p. 308. 
cesidad del bien. Sólo en la permanencia del bien, teniendo como objetivo a Dios, sumo Bien, puede el hombre ser verdaderamente libre y feliz. Esta necesidad en modo alguno va contra nuestra naturaleza que necesariamente busca la felicidad y ésta sólo puede darse cuando estamos en posesión del Bien.

El primer hombre recibió el don de poder no pecar pero hizo mal uso de él y abocó a la humanidad a un estado de imperfección que requería un auxilio especial de Dios: la Redención y continua ayuda a travẻs de la gracia. Si el hombre permanece fiel a ésta, entonces podrá, poco a poco, lograr en esta vida la liberación, hasta alcanzarla de modo pleno en la otra, en la que ya no podrá hacer el mal y tendrá asegurada su permanencia en el bien. La auténtica libertad agustiniana no es posibilidad de elección entre el bien o el mal sino necesidad del bien e imposibilidad del mal, la libertas. Sólo el Bien nos hará libres.

Frente a las tesis ateas que ven la liberación del hombre en su total autonomía y en la negación de Dios, san Agustín la concibe como un acercamiento progresivo a Dios ${ }^{54}$. Cuanto más cerca estemos de Él más libres seremos y viceversa, cuanto más alejados nos encontremos, menos libremos seremos. Es toda una muestra de nuestra entidad metafísica de criaturas y de nuestra dependencia de Dios, tanto en el orden del ser como en el orden del obrar. En definitiva, no hay libertad verdadera sin Dios.

María del Carmen Dolby Múgica e-mail: cdolby@aliso.pntic.mec.es

54 Dolby Múgica, C., «Antropología teísta: San Agustín. Antropología atea: Jean-Paul Sartre», en Pensamiento, 49 (1993), pp. 99-115. 